\title{
Bullous fixed drug eruption
}

\section{Palamino Hind, Siham Belmourida, Mariame Meziane, Nadia Ismaili, Leila Benzekri, Karima Senouci}

Dermatology-Venereology Department, CHU Ibn Sina, Rabat, Morroco

Corresponding author: Dr. Palamino Hind, E-mail: plmnhind@gmail.com

Sir,

Fixed drug eruption is a rare drug-induced toxicity. The bullous form is even more so. We are reporting here a case of generalized fixed drug eruption characterized by its bullous shape caused by the use of Diclofenac.

A 52 years old women with no medical history, was admitted to the emergency for generalized bullous eruptions that occurred approximately 24 hours after taking Diclofenacas self-medication.

Clinical examination revealed flaccid bullae over erythematous patches with post-bullous eruptions and superficial skin detachment reaching the trunk, abdomen, buttocks and thighs with no signs of Nikolsky, and large rounded pigmented patches were noted (Figs. 1 - 3).

The cutaneous area that was reached was estimated at $50 \%$ of the cutaneous surface. There was no damage to the mucous, and the general condition was preserved.

The standard biological assessment was normal and the cutaneous biopsy showed signs of drug eruptions, and the direct immunofluorescence was negative. The stop of the drug (only treatment taken by the patient) and the local cares allowed a good evolution of the skin lesions.

Fixed drug eruption is a recurrent, nearly pathognomonic rash of toxidermia. The generalized bullous eruption is pretty rare and one must think about the fact that it could be a toxic epidermic necrolysis [1].

The drugs most commonly inducing are tetracyclines, sulfonamides, penicillins, sulfone, pyrazolones, barbiturates, phenolphthalein, aspirin, paracetamol and oral contraceptives [1].

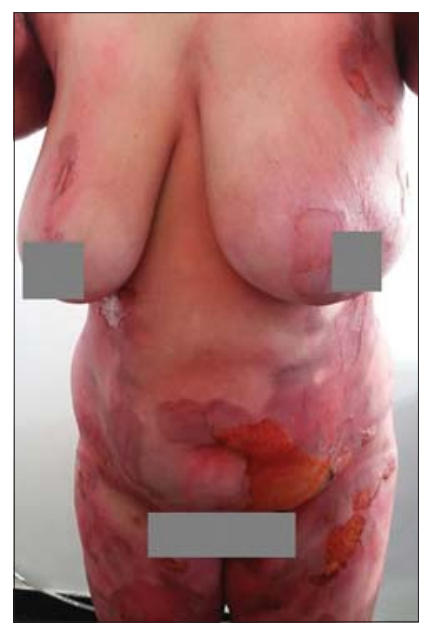

Figure 1: Flaccid bullae over erythematous patcheswith post-bullous eruptions and superficial skin detachment reaching the trunk, abdomen.

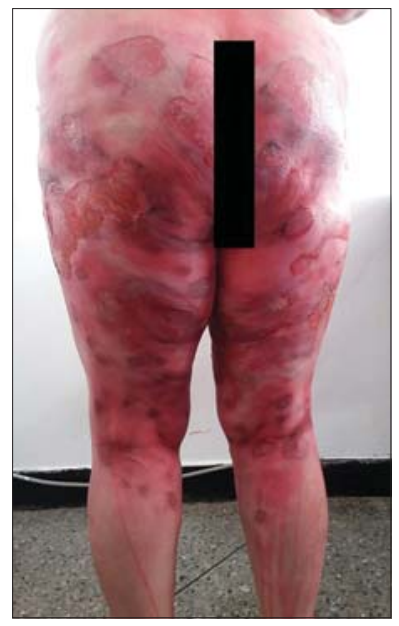

Figure 2: Flaccid bullae over erythematous patcheswith post-bullous eruptions and superficial skin detachment reaching on the buttocks and thighs, and rounded pigmented on the legs and on the thighs.

This dermatological condition can reach all parts of the body but preferentially reaches the extremities of the limbs, oral mucosa and ano-genital mucosa. The initial 


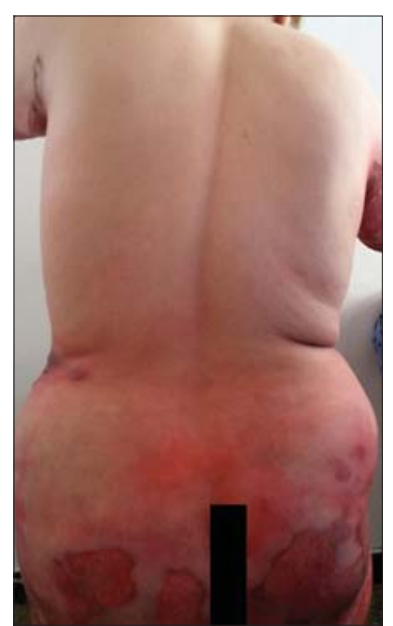

Figure 3 : Superficial skin detachment on the buttocks (no eruptions on hidden areas).

lesion, a well-delimited erythematous macula evolving towards the formation of vesicles and sometimes a bullous form, appears in the hours that follow the ingestion of the responsible drugs. After each new contact with the drugs, the lesion reappears at the same place and will frequently heal leaving room for residual pigmentation. The histological examination typically reveals a sometimes convergent keratinocytic necrosis that may be responsible for subepidermal detachment such as the case of our patient. Fixed drug eruption is a model of delayed hypersensibilityin reaction with CD8- T-cells and its treatment based mainly on the identification and eviction of the responsible molecule $[2,3]$.

For our patient, we decided to keep the diagnosis of fixed drug eruption because the lesions appeared quickly during the following hours after Diclofenac had been taken and because of the clinical and histological aspect but also the positive evolution under local cares.

The interest of our observation lies in the bullous and extensive character of the fixed drug eruption.

\section{Consent}

The examination of the patient was conducted according to the principles of the Declaration of Helsinki.

The authors certify that they have obtained all appropriate patient consent forms, in which the patients gave their consent for images and other clinical information to be included in the journal. The patients understand that their names and initials will not be published and due effort will be made to conceal their identity, but that anonymity cannot be guaranteed.

\section{REFERENCES}

1. Tounkara TM, Baldé H, Soumah MM, Bangoura M, Diané BF, Keita M, et al. Severe cutaneous drug reactions in Guinean children: a monocentric retrospective study of 35 cases. Our Dermatol Online. 2018;9:118-22.

2. Hoetzenecker W, Nägeli M, Mehra ET, Jensen AN, Saulite I, Schmid-Grendelmeier P, et al. Adverse cutaneous drug eruptions: current understanding. Semin Immunopathol. 2016;38:75-86.

3. Chaoui R, Douhi Z, El Kadiri S, Oukarfi S, Elloudi S, Baybay H, et al. Bullous fixed drug eruption secondary to dietary supplement. Our Dermatol Online. 2019;10(e):e43.1-e43.3.

Copyright by Palamino Hind, et al. This is an open-access article distributed under the terms of the Creative Commons Attribution License, which permits unrestricted use, distribution, and reproduction in any medium, provided the original author and source are credited.

Source of Support: Nil, Conflict of Interest: None declared. 